\title{
A língua como pátria ou a língua como direito? A identidade de um estrangeiro professor de PLE $^{1}$
}

\author{
Gabriel Nascimento ${ }^{2}$ \\ Universidade Federal do Sul da Bahia, Itabuna, BA, Brasil
}

Maria D'Ajuda Alomba Ribeiro ${ }^{3}$

Universidade Estadual de Santa Cruz, Ilhéus, BA, Brasil Universidade Federal de Roraima, Boa Vista, RO, Brasil

Resumo: O presente artigo questiona a ideia de língua como pátria no mundo moderno, de maneira a criar a categoria de "estrangeiro" e "conterrâneo" no ensino de Português como Língua Estrangeira (PLE). Para complicar essa discussão com fins de aprofundar essa questão, trazemos contribuições da área de identidade e ensino-aprendizagem de línguas, a visão de língua como invenção, inclusive no ensino de PLE, e um histórico da pesquisa e realização de cursos no PLE com vistas a questionar o papel do acolhimento, a identidade e a contribuição de um professor de PLE que é participante desta pesquisa. Seus dados, coletados através de um estudo de caso que, neste artigo se apresenta como uma história de vida, revelam que a "desestrangeirização" por meio de uma abordagem comunicativa no ensino de línguas, e, sobretudo no PLE, não pode se tornar uma categoria construída somente pelo viés do especialista/professor "nativo" banco de PLE, mas uma categoria co-construída com o desejo do aprendiz. Por último, reforçamos a necessidade de se ver a língua como direito, como espaço onde os sujeitos podem existir legitimamente.

Palavras-chave: Língua como pátria; Língua como direito; PLE.

Title: Language as a motherland or language as a right: the identity of a foreigner teaching Portuguese as a foreign language

Abstract: This article questions the idea of language as a motherland in the modern world that urges the category of "foreigner" and "fellow citizen" in the teaching of Portuguese as a Foreign Language (PLE). To further this issue, we will draw on the contributions from research on identity and language learning, the vision of language as an invention, including the PLE teaching, and the history of PLE teaching in Brazil to posit the role of welcoming, the identity and collected data from a PLE teacher. The results point to

\footnotetext{
${ }^{1}$ Este trabalho é um desdobramento de pesquisa do Grupo de Pesquisa em Linguagem e Racismo (UFSB). Além disso, esta pesquisa foi apoiada parcialmente com bolsa Capes (DS).

2 Professor da Universidade Federal do Sul da Bahia. Doutor em Letras pela Universidade de São Paulo e mestre em Linguística Aplicada pela Universidade de Brasília. É líder do Grupo de Pesquisa em Linguagem e Racismo. Orcid: http://orcid.org/0000-0002-7695-9264. E-mail: gabriel@ufsb.edu.br.

${ }^{3}$ Professora emérita da Universidade Estadual de Santa Cruz. É doutora em Linguística Aplicada pela Universidade de Alcalá de Henares, com mais de uma década atuando em programas de pós-graduação como professora permanente e coordenadora, dentre os quais o Programa de Pós-graduação em Letras (UESC), o Mestrado Profissional em Letras (UESC), em rede nacional e o Programa de Pós-graduação em Letras (UFRR), onde é professora visitante (Programa de Professor Visitante Nacional Sênior na Amazônia). Orcid: http://orcid.org/0000-0002-9183-9076. E-mail: profdajuda@gmail.com.
} 
critiques over the "non-foreign" remarks on PLE teaching that aims at making the teaching more profitable for foreigners learning Portuguese as a second language. The results also point out that the communicative approach in language teaching, while downplaying the existence of "non-foreign" status in the teaching of PLE must not be constructed only by the gaze of teacher/scholar, who is at times white and "native", but as a co-construction with the desire arising from the learner as well. Finally, we will back the need for analyzing language as a right, whereby subjects can exist legitimately.

Keywords: Language as a motherland; Language as a right; PLE.

\section{Introdução}

Gosto de sentir a minha língua roçar a língua de Luís de Camões

Gosto de ser e de estar E quero me dedicar a criar confusões de prosódias

E uma profusão de paródias

Que encurtem dores E furtem cores como camaleões Gosto do Pessoa na pessoa

Da rosa no Rosa

E sei que a poesia está para a prosa Assim como o amor está para a amizade E quem há de negar que esta lhe é superior? E deixe os Portugais morrerem à míngua

Minha pátria é minha língua

("Língua"- Caetano Veloso)

O poema-música de Caetano Veloso, cujo trecho se encontra em destaque acima, embora supostamente exaltando a diversidade linguística brasileira, termina com o verso de Fernando Pessoa que inspira, em boa medida, este artigo. Se a pátria é a língua, a língua necessariamente passa a ser a pátria? Essas perguntas fenomenológicas nos levam a uma relação de alteridade com a língua como pátria que tem sido aquele que é estranho à língua/pátria, que é o estrangeiro.

Embora a própria noção do uso da palavra "estrangeiro" na língua seja objeto, já há alguns anos, de crítica na área de Linguística Aplicada, entendendo-se que, ao aprender uma língua estrangeira, a mesma é desestrangeirizada (ALMEIDA FILHO, 1993), optamos pelo uso da palavra "estrangeiro" o aqui justamente para problematizar o pensamento liberal do multiculturalismo (em boa parte influenciado pelos estudos sociológicos norte-americanos) que, ao rebater a ideia de "pátria/língua", buscando desestrangeirizar o estrangeiro na língua, volta a reafirmar ambos (pátria/língua), através da necessidade de deixar de ser estrangeiro, como pressuposto. 
Neste trabalho com enfoque na aprendizagem ${ }^{4}$ de Português como Língua Estrangeira e identidade no ensino-aprendizagem de línguas, partimos de considerações da Linguística Aplicada para buscar entender a relação entre pertença e sujeito na aquisição/aprendizagem de Português como Língua Estrangeira (de agora em diante chamaremos de PLE apenas) ${ }^{5}$.

A Linguística Aplicada tem permitido, nos últimos anos, arregimentar uma crítica coesa sobra a relação entre identidades e ensino-aprendizagem de línguas (BERTOLDO, 2003; MASTRELLA-DE-ANDRADE, 2010, 2011; FERREIRA; CAMARGO, 2013; LEFFA, 2013; TÍLIO, 2010; NASCIMENTO, 2014). Dessa crítica depreendemos a necessidade emergente de analisar como os estudantes, que já conseguem se comunicar numa segunda língua, são atravessados por questões de pertença à cultura dessa língua, inclusive havendo generalizações de maior conforto ou menor conforto em relação àquela língua que está aprendendo a partir de sua cultura, como é o caso da defesa da "desestrangeirização" da língua estrangeira como forma de tornar a língua mais confortável para quem aprende (ALMEIDA FILHO, 1993). Assim, queremos saber de que modo a identidade do falante está marcada por sua relação com a cultura da língua, e como ele se porta diante dessa cultura, de forma a pensar, sob o guarda-chuva de uma herança brancocentrada ocidental, se língua é pátria, e vice-versa. As perguntas que surgem são: De quem é a língua-alvo? Uma língua tem donos?

É fundamental discutir e desconstruir alguns desses conceitos e essa proposta será desenvolvida no decorrer deste trabalho por meio da visão de língua como uma invenção (MAKONI; PENNYCOOK, 2007), que, embora seja reificada pelo linguista, não passa de um regime metadiscursivo assim imposto a partir da conformação de línguas nacionais europeias. Dessa forma, as chamadas línguas neolatinas, ao serem padronizadas a partir de modos de falar supostamente similares, passam a figurar como línguas modernas (NASCIMENTO, 2019). No entanto, essas são invenções de si e de uma modernidade que elege língua como sua bandeira evolutiva, sendo essas línguas os objetos que passam a representar os povos brancos no ocidente, onde língua, segundo Fanon (2008), dentro de uma dada escala evolucionária, representa o humano (branco) frente ao não-humano (negro, e demais não-brancos).

Primeiramente, vamos falar sobre língua como invenção para localizar de que maneira, a partir da língua como invenção (MAKONI e PENNYCOOK, 2007), a noção se estrangeiro na língua é inventada. Em seguida, faremos um histórico do ensino de línguas estrangeiras no país, tendo em vista como se conforma a ideia de estrangeirização da língua estrangeira.

Para confrontar a ideia de língua como pátria e vice-versa, vamos analisar dados obtidos com um professor de PLE estrangeiro residente no Brasil. Os dados analisados neste

\footnotetext{
${ }^{4}$ Propositalmente, e não sendo filiados às teorias cognitivistas de aquisição/aprendizagem, não fazemos aqui nenhuma distinção dessas duas categorizações.

${ }^{5}$ Embora tenhamos plena consciência das várias formas de se chamar esse ensino, optamos pelo PLE justamente por estar em questionamento a categoria do Estrangeiro que, inclusive, compõe a sigla.
} 
artigo fazem parte de um estudo de caso, cujos instrumentos adotados são característicos de uma história de vida. Nesta pesquisa, o falante/professor de português é oriundo da América Central. Alguns resultados obtidos através de sua história de vida mostram que, embora o falante seja muitas vezes reconhecido como brasileiro, pela semelhança entre a cultura brasileira e a cultura de seu país, e pela forma fluente como fala o português brasileiro, o participante não se autodeclara brasileiro, demarcando uma categoria de "estrangeiro". Assim, usufrui culturalmente da naturalidade com que fala o Português, e que é tratado a partir dessa fala, mas sempre demarca posição de origem e tem uma narrativa de mundo enfocada na relação de pertença entre as duas línguas, e não necessariamente em um dos polos da invenção linguística ligada à ideia de pátria.

\section{Identidade e ensino-aprendizagem de línguas}

Pesquisador: Qual é a imagem que você faz de si mesmo falando essa língua? Participante: Ah, eu acho que não falo bem. Pesquisador: Mas as pessoas dizem que você fala bem? Participante: Sim, mas eu não acho.

(Trecho de entrevista semiestruturada com professor estrangeiro de português atuando no Brasil)

A relação entre identidade e ensino-aprendizagem de línguas é permeada, inicialmente, na relação entre sujeito e história. Os fenômenos globais e históricos que nos trouxeram ao momento atual impactam o ensino-aprendizagem de línguas (MASTRELLA-DEANDRADE, 2010). Entre eles, damos destaque à globalização, por ser uma força catalisadora que aglutina e desloca os centros de poder (HALL, 1999; SANTOS, 1999; BRETÃS, 2003), reforçando as desigualdades através da concentração máxima do capitalismo em nível global (SANTOS, 2000) e permitindo a construção de identidades. A construção de identidade, portanto, é vista por nós como uma posição de fronteira, já delineada pelos chamados teóricos decoloniais (MIGNOLO, 2000) e chicanos (ANZALDUA, 1987), cuja condição de fronteira é imposta pelo branco, colonizador, imperialista, neoliberal, e não uma escolha do sujeito no mundo liberal democrático.

Ao examinar a identidade cultural na pós-modernidade, Hall (1999) introduz a noção de identidade através da construção de três sujeitos fundamentais: o sujeito iluminista, o sujeito sociológico e o sujeito pós-moderno. A identidade do sujeito iluminista, filho da revolução francesa, se apresenta através de um indivíduo centrado, unificado e racional. 0 exemplo desse sujeito está na leitura do cidadão através do contrato social a partir de Rousseau. O segundo sujeito é o sociológico, cuja identidade é definida frente ao coletivo, enfrenta a complexidade do mundo moderno e tem que se relacionar com as problemáticas culturais, porém partindo de lugares objetivos na cultura. O exemplo desse sujeito são as contradições culturais advindas da industrialização, em que homens e mulheres são colocados em diversas posições sociais. É o caso da mulher que é mãe e trabalhadora fabril. A última identidade, reforçada a partir da globalização, é a identidade do sujeito pósmoderno. Ao contrário dos demais, esse sujeito não tem lugar fixo na cultura e as 
contradições são emergentes de sua prática social e discursiva. Esse sujeito tem identidade fragmentada, transitória e ambivalente.

No entanto, a relação entre identidades e ensino-aprendizagem de línguas advém também da marcante presença de conflitos nas práticas pedagógicos que englobam práticas de poder que influem para a construção de paradigmas educacionais muitas vezes excludentes (NORTON; TOOHEY, 2011). Se a relação entre educação e identidades permite concluir que há nas práticas educacionais a presença de práticas de poder, isso fica mais contundente quando o objeto teórico e empírico é a linguagem e sua apropriação.

Os trabalhos que discutem identidades no ensino-aprendizagem de línguas permitem identificar que múltiplas identidades são impactadas por esse aprendizado e que impactam esse aprendizado. Entre elas as identidades etnicorraciais (FERREIRA; CAMARGO, 2013), de sexualidade (TÍLIO; JÚNIOR, 2014) e de classe social (MASTRELLA-RODRIGUES, 2014; VANDRICK, 2014; SANTOS, 2016).

Ferreira e Camargo (2013) analisam de que forma o livro didático (doravante) de língua inglesa constrói um racismo cordial através da subrepresentação da identidade negra. Esse racismo converge com o silenciamento e subrepresentação dessas identidades, em que o livro estereotipa o negro.

Tílio e Júnior (2014), por sua vez, observam como as identidades de sexualidade são construídas em LD de língua inglesa e concluem por uma ligação negativa da palavra sexualidade com DSTs, sexo etc. Ou seja, a sexualidade não possui dimensão mais humana e afetiva, e apenas biologicista e ligada às questões de saúde, fazendo com que estereótipos sejam construídos.

E, finalmente, Mastrella-de-Andrade e Rodrigues (2014), Vandrick (2014) e Santos (2016) têm pesquisas distintas que trazem inúmeros resultados. Vandrick (2014) analisa o contexto educacional e pedagógico do ensino-aprendizagem de línguas e verifica a necessidade de maior atenção da Linguística Aplicada com questões de classe social. Mastrella-de-Andrade e Rodrigues (2014), ao analisar como identidades de classe social são construídas no LD, concluem que as atividades sugeridas pelo livro são, em geral, contextualizadas através do enfoque do Lazer como item que se passa em lugares luxuosos, em que apenas classes sociais mais privilegiadas podem acessar. Nessa mesma direção, Santos (2016) afirma haver um continuum de subrepresentação e apagamento das classes mais populares no livro didático em que, quanto mais populares são as classes, mas as personagens não aparecem ou aparecem esporadicamente construídas ou em posição subalternada e não problematizada.

Essas pesquisas, assim, têm apontado para a necessidade de analisar as mais diversas constituições de identidade que não necessariamente são um porto de passagem ou uma escolha liberal no ensino de línguas, mas, como destaca Block (2013), podem ser reprodução das próprias desigualdades sociais (e, acrescento, raciais) no ensino de línguas.

A seguir vamos esboçar melhor nosso entendimento do que seja língua e suas implicações para a ideia de língua como pátria. 


\section{Língua como pátria - uma invenção racista}

"Meu querido, vou te confessar uma coisa. Às vezes eu me pego corrigindo as pessoas. Eu ouço elas dizerem as coisas, por exemplo, "interviu".

(Trecho de entrevista semiestruturada com professor estrangeiro de português atuando no Brasil)

As línguas normalmente têm sido vistas como realidades materiais, como realidades factuais e como fenômenos da própria natureza humana. Temos visto isso nos estudos cognitivistas de base sociológica que herdam de maneira abundante o teor de análise evolucionária que produziu a noção de humano nas ciências "naturais". Essa é uma das razões que levam o intelectual negro martinicano Aimé-Cesaire (1971) a rejeitar categoricamente o humanismo como uma concepção universal. Para ele, o humanismo cria a agenda evolucionária que elege primeiramente o branco como humano e os não-brancos como selvagens. Fartos são os documentos coloniais que ratificam essa ideia, como é o caso do Diretório que se deve observar nas povoações dos índios do Pará e Maranhão ${ }^{6}$, figurando como a primeira política pública promulgada expressamente pelo reino português a impor uma língua nacional no país, o Português.

Línguas não existem enquanto realidade material e nem como fenômeno de nenhuma natureza (MAKONI; PENNYCOOK, 2007). O que faz com que línguas sejam reconhecidas como "naturais" é uma ideologização de sua estrutura (SILVERSTEIN, 1979), permitindo o surgimento de uma "naturalização" linguística (ROSA; FLORES, 2017), como se língua fosse mesmo algo real.

O linguista tem par nisso, segundo Makoni e Pennycook (2007). Ao analisar língua, esse analista muitas vezes a reifica e passa a tratá-la como se fosse real. Segundo os autores, fartos são os exemplos na área de política linguística, sociolinguística ou psicolinguística, que delimitam uma língua como um organismo vivo, cujas fronteiras passam a criar categoria metafísica própria, como se não houvesse uma anterioridade.

Esses autores tratam língua como invenção para expressar o próprio fim do mito de uma modernidade que, ao criar o branco como seu sujeito central, criou línguas nacionais como a fala global desse branco.

As relações entre língua e pátria podem ser localizadas no trabalho de Anderson (1991), para quem a Europa é uma imaginação de si, buscando aprofundar a imaginação da modernidade. Por isso, para ser o que é, o sujeito moderno precisava criar e conformar os conceitos de nação, língua, bandeira, hino, território, constituição etc. Movimentos brancocentrados como lluminismo, Romantismo ou Modernismo são exemplos nítidos de confirmação desse espírito moderno, mesmo em suas dissidências.

\footnotetext{
${ }^{6}$ Disponível em:

<https://www.google.com/url?sa=t\&rct=j\&q=\&esrc=s\&source=web\&cd=3\&ved=2ahUKEwiz_9jH7rPpAhXLLLkG HVzpCxcQFjACegQIAxAB\&url=http\%3A\%2F\%2Flemad.fflch.usp.br\%2Fsites\%2Flemad.fflch.usp.br\%2Ffiles\%2F20 18-04\%2FDiretorio_dos_indios_de\%2529_1757.pdf\&usg=AOvVaw0DP8uT45d-IfPOYVqsRTHu>. Acesso em 20 jan. 2021.
} 
Assim, língua e pátria passam a ser bandeiras de um mesmo pensamento moderno eurocêntrico que concebe aquele que tem língua e pátria como o europeu branco. Não bastasse isso, as elites do Sul, cuja inspiração está nos brancos do norte (SOUZA, 2018), passam a reproduzir essa meta narrativa de si, mesmo não sendo muitas vezes consideradas no Norte como pessoas com-língua. Dessa forma, língua nacional passa a ser sinônimo de língua. Ter língua é falar uma língua nacional.

Por isso a ideia de desestrangeirização, como defendida em Almeida Filho (1993) é problemática. O autor destaca que, pela via da comunicação, ao aprender essa língua, o falante pode se desapegar aos poucos de suas normas específicas e praticar uma variante franca dessa língua na comunicação, desestrangeirizando a língua para si.

No entanto, a amplitude das discussões de Makoni e Pennycook (2007), Irvine e Gal (2000) permite consagrar a ideia de que a ideia de língua franca é a invenção global de uma dada língua, que se torna mais um aparato monolíngue. Esse aparato monolíngue, que desconstrói o lugar supostamente neutro de uma língua franca como o inglês, é o que vem tornando o multilinguismo uma utopia (STROUD; QUENTIN, 2017), em que as práticas multilíngues modernas se apropriam das práticas pré-coloniais como as africanas e passam a reproduzi-las como se isso fosse uma invenção do homem branco moderno (CANAGARAJAH; LIYANAGE, 2012).

Assim, o que se chama de desestrangeirização como teorizado através de uma aproximação de um lugar neutro de uma variante franca de uma língua como o inglês é, muito apropriadamente, a apróximação de uma dada variante global influenciada por uma variante dominante daquela língua. Smitherman (1998), por exemplo, explica que a variante mais conhecida do inglês internacionalmente é justamente aquela falada pelo branco norteamericano.

Assim, a ideia de desestrangeirização no aprendizado de uma língua estrangeira alimenta a visão de línguas modernas como construtos universais, baliza a ideia de pátria como seu pressuposto (porque se há o estrangeiro também há a pátria) e produz o branco como o padrão na língua.

Afirmamos, como em Nascimento (2019), que a própria noção de língua tem servido para alimentar teses cognitivistas, como a de que o falante nativo de uma dada língua tem superioridade perante o falante não-nativo (NORTON, 1997; BYRAM, 1997; PAVLENKO, 2003; KUBOTA, 2009).

Neste artigo veremos que a noção de fluência do estudante o integra a essa pátria linguística, que é racista porque vem de teses de uma agenda evolucionária das línguas modernas, mas que não necessariamente precisa ser desestrangeirizada para ser mais "natural" ao falante "nativo".

Menezes de Souza (2018), em um conto com matizes autobiográficas, ironiza a ideia de identidade nacional na língua. Sua personagem, ao se consultar com um psiquiatra, dribla a sua origem diversas vezes, fazendo o médico se perder em seus próprios labirintos nacionais. A personagem, nascida originalmente no lêmen sob o julgo colonial britânico, é de família indiana, que vem de Goa, que não necessariamente se considera parte da nação 
indiana. Para piorar, a personagem tem cidadania britânica, e foi forjada numa identidade de "black" na Londres branca, o que o despoja de uma naturalidade cidadã no mundo britânico brancocentrado. Suas palavras, que desorganizam a lógica de naturalidade nativa do falante inglês britânico banco, que olha a língua como sua propriedade, o dilaceram:

Muitas vezes, em visitas de trabalho a uma universidade inglesa, encontrava um amigável acadêmico inglês na máquina de café da sala dos funcionários que, ao ver meu rosto de Goa, fazia a pergunta: "De onde você é? Você fala inglês tão bem?". Com a inocência da minha juventude perdida há muito tempo, eu respondia, sorrindo, do alto da minha cidadania goense: "Oi! Eu sou da educação. De onde você é? Seu inglês também é muito bom!" (SOUZA, 2018, p. 428, grifos nossos) ${ }^{7}$.

Portanto, a visão de língua como pátria passa a ser a principal inimiga de um construto de língua que se quer mais equitativa para os falantes que não vêm de privilégios raciais eurocêntricos. A pátria e a língua se tornam as duas uma coisa só, como a paráfrase que abre este artigo, reificando o sujeito na língua, e vice-versa.

A seguir vamos contextualizar o ensino de línguas estrangeiras no Brasil com vistas a compreender o lugar do ensino de Português para estrangeiros.

\section{A política de ensino de língua estrangeira como criação da noção de língua/pátria}

Pesquisador: Você sente que o fato de você falar fluentemente o Português aproxima você das pessoas?

Participante: Sim, eu acho que sim, porque a língua é a comunicação, né? Aí se eu não tou conseguindo me comunicar com você eu nunca vou me aproximar. Mas, sim, eu acho que o fato de eu falar Português, ele já ajudou para que eu conhecesse mais pessoas.

(Trecho de entrevista semiestruturada com professor estrangeiro de português atuando no Brasil)

A comunicação humana e a expressividade estão sempre presentes entre as pessoas que não falam a mesma língua. É com base nesse enunciado que nos apoiamos nas autoras Machado et al. (2007) para fazer um pequeno recorte do ensino de línguas estrangeiras no Brasil, observando os aspectos principais desse percurso. Essa análise permitirá, portanto, entender como a própria história do ensino de línguas estrangeiras ratifica a ideia de língua como pátria. Inicialmente, as autoras destacam três importantes momentos, sendo eles a Reforma Francisco de Campos, em 1931, a Reforma Capanema, em 1942, e a publicação da primeira Lei de Diretrizes e Bases da Educação, em 1961.

A década de 20, por exemplo, suscitou uma crise envolvendo vários movimentos que levaram à derrubada do Presidente Washington Luiz e a implantação do Governo Provisório de Getúlio Vargas. Com a Revolução de 1930, o contexto político e econômico colocou em pauta a estrutura do ensino vigente no país e Getúlio Vargas, ainda durante sua posse, garante o "programa de reconstrução nacional" onde previa a necessidade da difusão

\footnotetext{
${ }^{7}$ Tradução nossa.
} 
nacional do ensino público, com a criação de um sistema nacional com participação direta dos estados federados.

É nesse viés que a educação passa a ter um papel fundamental na ideia de formação nacional e modernização do país, que cunha e reproduz aqui um sentimento nacional atrelado às comunidades imaginadas europeias (ANDERSON, 1991). Embora progressista, o governo de Getúlio criava uma nacionalidade brancocentrada baseada na prevalência dos brancos sobre os negros numa política eugenista, ao passo que exaltava a suposta unidade morena da nação (que era, em base, branca e baseada nesses fenótipos, como afirmado em NASCIMENTO, 2019).

Criava-se, assim, o Ministério dos Negócios da Educação e Saúde Pública pelo decreto no. 19.402 de 14 de novembro de 1930 e Francisco de Campos assumia como seu primeiro titular no dia 18 de novembro daquele mesmo ano. Na atuação como ministro, Francisco de Campos reformou toda a estrutura do ensino brasileiro na tentativa de adaptar o sistema de ensino à nova realidade do país, instituindo-se através de uma série de decretos e portarias, uma política nacional de educação. O maior destaque dessas medidas foi a criação do Conselho Nacional de Educação, a organização do ensino superior e a adoção do regime universitário, a organização do ensino secundário.

Posterior a essa reforma, a Reforma Capanema não só continua a abastecer um sistema de ensino secundário com ampliação do ensino de línguas estrangeiras, como também estabeleceu que o Português, confirmando o Diretório que se deve observar nas povoações dos índios do Pará e Maranhão, era a língua nacional. Exemplo disso é o alvará a seguir.

Figura 1 - Alvará É proibido falar os idiomas alemão, italiano e japonês

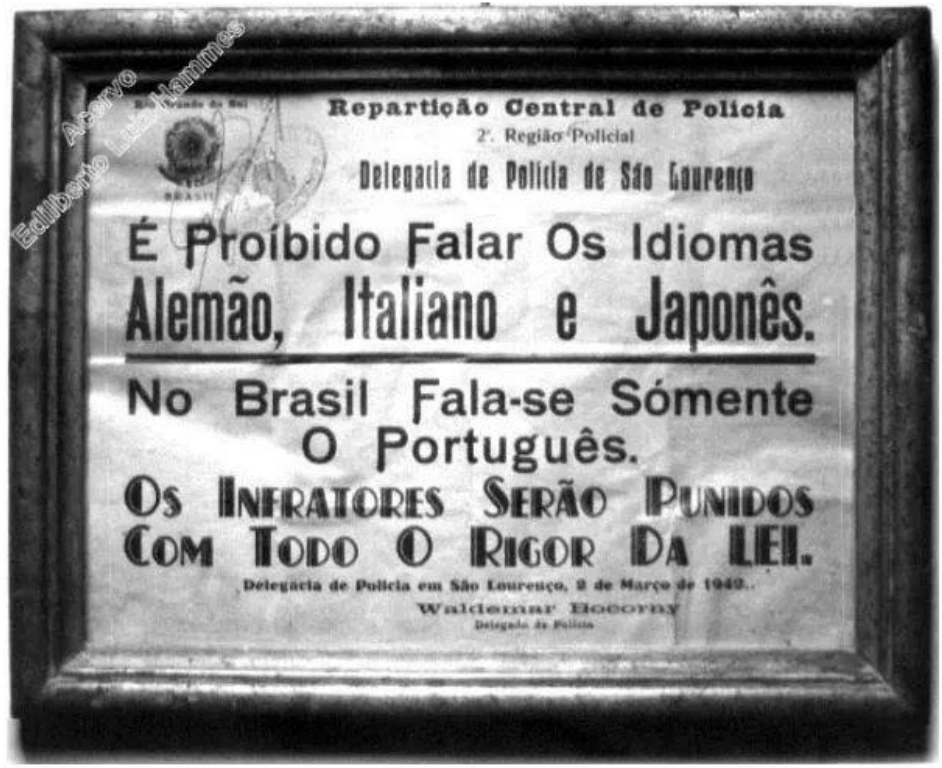

Fonte: Acervo Edilberto Luiz Hammes. Disponível em: retirado do site http://www.germanofonia.com/motivo-03-o-alemao-ja-foi-proibido-no-brasil/

Acesso em: 24 fev. 2021. 
Muitos autores, dentre os quais Rocha (2004), têm trazido essa questão com enorme protesto, inclusive sinalizando que esse período, concebido como campanha de nacionalização, sujeito identidades estrangeiras a um monolinguismo obrigatório do português. Entretanto, pouca atenção é dada aos negros brasileiros que, conforme o nosso participante nesta pesquisa, foram obrigados a ser abrasileirados na língua, tendo que apagar as suas línguas banto, por exemplo. Mais do que isso, como analisa Castro (2011), esses falantes foram abrasileirados, numa herança colonial que denominamos colonialidade (MIGNOLO, 2000), mas suas marcas de africania persistem, porém apagadas.

Assim, a Pátria não foi construída na língua na década de 30, com o nacionalismo varguista, mas com a própria colonialidade branca e escravocrata que, persistentemente, impôs um monolinguismo aos povos racializados negros e indígenas (NASCIMENTO, 2019). É na década de 30, porém, que o nacionalismo rompe com o imigrantismo sudestino, cuja tendência de imigração para com o intuito de branquear o povo brasileiro começou na década de 40 do século XIX (AZEVEDO, 1987). Assim, a escravidão teria acabado também como forma dos brancos brasileiros interromperem um ciclo de enegrecimento e miscigenação da população branca. Por outro lado, interpretamos no rompimento de Getúlio com o sudeste em 1930 o próprio rompimento com o imigrantismo, que o leva à proibição de línguas de povos imigrantes brancos ou amarelos, reproduzindo o que aconteceu, com teor racista, com os povos negros e indígenas desde muitos séculos antes.

Assim, a perspectiva a partir daí só confirma uma visão eurocêntrica e brancocentrada, mesmo combatendo línguas de povos imigrantes brancos. Isso porque se trata de uma disputa dos brancos de uma região contra os brancos de outras regiões (após o rompimento da Política do Café com Leite) ${ }^{8}$ pelo poderio nacional.

Mais do que isso, as elites nacionais vigentes na década de 30 são aquelas que estão de uma forma ou outra reafirmando a ideia de pátria como língua e língua como pátria. $A$ criação da língua estrangeira como política pública nas escolas regulares é um exemplo de uma política que busca valorizar línguas nacionais modernas ou homenageadas pelo mundo moderno como exemplos de língua no mundo antigo (como as línguas brancas Grego e Latim).

\section{Do ensino de PLE ao ensino do português como língua de acolhimento}

Pesquisador: Você acha que você é desestrangeirizado pras pessoas quando você fala um Português mais fluente? Participante: Pras pessoas sim.

(Trecho de entrevista semiestruturada com professor estrangeiro de português atuando no Brasil)

Embora se reconheça que o ensino Português como Língua Estrangeira (PLE) existe desde a colônia (ALMEIDA FILHO, 2011), com a evangelização colonialista dos povos

\footnotetext{
${ }^{8}$ Ver mais em https://educacao.uol.com.br/disciplinas/historia-brasil/governo-washington-luis-1926-1930-fimda-republica-velha.htm. Acesso em 24 fev. 2020.
} 
indígenas pelos jesuítas, a expansão dessa forma de ensino da língua portuguesa assim nomeada se dá a partir do trabalho de Marchand (1957), quando da publicação de Português para Estrangeiros.

Interessante notar que indígenas e negros são vistos como estrangeiros desde o período colonial, sendo que tinham que aprender a uma língua portuguesa de maneira forçada como estrangeiros que eram. Em segundo lugar, cumpre salientar que a ampliação do ensino de português como língua estrangeira acontece somente a partir da década de 60, quando o governo militar passa a fornecer subsídios para extensão da política de ensino de língua estrangeira para atender a expansão do capitalismo em nível global (como destaca ALMEIDA FILHO, 2005, destaca, o surgimento da Linguística Aplicada nos Estados Unidos é resultado desse contexto).

Como Gomes de Matos (1997) nos lembra, por exemplo, que ele lecionava em Recife em meados da década de 50 e que o então material disponível era importado dos Estados Unidos, sendo ele o livro Spoken Brazilian Portuguese, de origem do Foreign Service Institute, de Washington. Isso porque cursos de Português oferecidos no Brasil na década de 50 eram pouquíssimos e dependiam de textos escritos no exterior, principalmente nos Estados Unidos. ${ }^{9}$

Com isso, mais atualmente as preocupações sobre o ensino de Português como Língua Estrangeira têm se desenvolvido a partir da criação do Mercado Comum do Cone Sul (ALOMBA RIBEIRO, 2005) e a partir dos anos 2000 numa nova onda migratória (SÃO BERNARDO; BARBOSA, 2018; SÁ, 2017) resultante das desigualdades geradas pela globalização capitalista (SANTOS, 2000).

Nesses dois períodos, embora os esforços de instituições como a Sociedade Internacional de Português como Língua Estrangeira, não houve diretrizes nacionais correspondentes a uma institucionalização do Português como Língua Estrangeira ${ }^{10}$, ficando sua execução através de políticas isoladas nas instituições de ensino superior, dentre as quais a Universidade de Brasília por meio da criação do curso de Letras - Português do Brasil como Segunda Língua.

Apesar dos trabalhos nesse período terem se desenvolvido o suficiente, como o enfoque na formação de professores de PLE (SANTOS e ALOMBA RIBEIRO, 2013), interculturalidade no ensino de PLE (MENDES, 2011), entre outros, não houve a transformação dessa rica experiência em uma política de Estado.

Porém, como advogam São Bernardo e Barbosa (2018), é possível transformar o ensino de PLE como mais inclusivo para as pessoas não-brancas que chegaram ao país nessa nova onda migratória. As autoras advogam para a necessidade de se repensar a

\footnotetext{
${ }^{9}$ Para maiores informações, consultar Almeida Filho e Lombello (1997).

10 São exceções o CELPE-BRAS, que, embora tenha suas diretrizes, não se constitui em política de ensinoaprendizagem, e o parecer do Conselho Nacional de Educação sobre as Diretrizes Curriculares Nacionais para a Educação Bilíngue que, conforme disponível no link a seguir, ainda não foi institucionalizado pelo MEC. O link para acesso é http://portal.mec.gov.br/index.php?option=com docman\&view=download\&alias=146571-textoreferencia-parecer-sobre-educac-a-o-bili-ngue\&category slug=maio-2020-pdf\&Itemid=30192. Acesso em 24 fev. 2021.
} 
desestrangeirização do português para refugiados por meio de um ensino voltado para a tecnologia do acolhimento.

As autoras revelam, por exemplo, que as demandas desses estudantes são diferentes daquelas trazidas em contextos anteriores, em que outros estrangeiros não necessariamente precisavam ser acolhidos para construírem um aprendizado significativo de português.

O nosso participante, que vem sendo citado por meio de paráfrases desde o início do texto, não vem de um contexto de refúgio, mas construiu no português uma narrativa de aprendizado que permite problematizar os conceitos de língua como pátria e "estrangeiro", que compõe a sigla PLE e vem sendo substituída.

Esses dados, mais do que confundir, servem para fazer da confusão aquilo que Menezes de Souza (2019) chama de tradução cultural, isto é, o equívoco e confusão, como normalmente vistos pelo Ocidente, são nada mais, nada menos, um incentivo do mundo afroamericano e ameríndio à necessidade de pensar. Neste caso, o termo "estrangeiro" é contraposto à língua como pátria para desconstruir essa visão de invenção linguística que, de várias formas, pode ser reproduzida no ensino de PLE, e que constitui PLE como uma plataforma que reproduz a ossatura das línguas nacionais europeias, como se a língua falada atualmente no Brasil fosse a mesma língua trazida a este território no século XVI pelos invasores.

Assim, após contextualização e análise dos dados coletados, retornaremos a essa reflexão.

\section{José del Viega, um afrolatino? - uma história de vida}

Uma das coisas que aproximaram um dos autores deste texto do participante foi a identificação racial. Um, mestiço negro brasileiro, assim visto socialmente e em suas origens básicas familiares, e o outro, um mestiço latino, sempre discutiram questões raciais, no Brasil e na América Latina.

Uma das discussões que veem unidade heterogênea na América Latina é a visão de González (1988), que engloba ideia de uma Améfrica Ladina. Ao invés de reproduzir os mitos de latinidade até então, González entende a América Latina como racializada em consequência ao processo escravocrata. Mesmo sendo a mestiçagem uma forma de branqueamento, esses povos ainda não encontraram o status de branco como o perfil brancoide europeu e norte-americano pressupõe. Por isso, segundo ela, há uma unidade amefricana que pode ser resultado de uma racialização nessa região.

Invoco González para tratar do nosso participante, que nomearemos José del Viega para fins desta pesquisa. Advindo de um dos países da América Central, esse participante não necessariamente tem os traços brancoides valorizados no Brasil como marcas de cidadania (SOUZA, 1983). Porém, mesmo vindo de uma Améfrica Ladina, cuja miscigenação serviu para apagar os traços negroides e dos povos originários indígenas, o participante nunca se autodeclarou negro. Aliás, como revelou, e confirmando as pesquisas descritas em 
Telles (2014), a miscigenação em diversos países da América Latina fez expandir a categoria de branco, e não a de negro.

No caso do Brasil, revela Munanga (2004), a mestiçagem leva a uma sociedade branca mal resolvida, sendo ela própria mestiça, que passa a criar teorias de como se branquear. Para isso, surge o imigrantismo (com efeito muito forte nas populações sudestinas e sulistas), e teses sobre o quase-branco/quase-negro, que é o mulato. Não bastasse isso, profecias de fim dos negros e mestiços passam a se espalhar. ${ }^{11}$ Dessa forma, o nosso participante, ainda que de pele clara, pode ser lido dentro dessa passagem que o branqueamento brasileiro tem realizado, ainda não concluída.

No entanto, não se autodeclarar negro é como se declarar "estrangeiro". Não há uma categoria global do negro, mas condições profundamente regionalizadas pelo racismo, que é global. Assim, o fato do participante apenas se declarar latino, num país que não se considera latino, já merece grande vantagem na confusão que propõe o caráter desta pesquisa. Fanon (2008) e Gilroy (2001), ao falar de nacionalidade negra, analisam que o negro foi transformando numa categoria reificada, estrangeiro a todas as nações.

O fato do participante desta pesquisa não se autodeclarar negro não faz necessariamente fechado a aprender uma língua estrangeira como o português. $O$ interesse das conversas, que se tornaram entrevistas semiestruturadas, com vistas a construir uma história de vida desse falante/aprendiz, foram sobre o seu nível de fluência no português, e de que forma isso o integrava mais ou menos na cultura.

Professor de PLE em seu país, ele relata ter vindo ao Brasil exclusivamente por causa da língua. Isso foi justamente o ponto de clímax e encontro para esta pesquisa. À época, e ambos sob a discussão sobre a suposta autoridade do falante nativo sobre a sua língua, um dos autores deste texto lia com ele anúncios nos murais da universidade sobre cursos com falantes nativos de inglês.

Línguas não são pátrias, como queremos advogar aqui. Mas pátrias também só existem enquanto invenções modernas. Então, pátrias são arregimentações de poder, imaginações de si (ANDERSON, 1991) e racializações dos outros. Assim, as pessoas nascem num dado assentamento, espaçamento ou localização que necessariamente no mundo moderno passa a ser chamado de território, onde se funda uma pátria com sua língua. 0 monolinguismo passa a ser marca desse mundo moderno, pretendendo-se, inclusive, a criação de um multilinguismo monolíngue (STROUD; QUENTIN, 2017), com a exportação das línguas neolatinas como se fossem línguas nacionais a serem universalizadas.

Voltando A José del Viega, o pesquisador que o entrevistou sempre estranhava durante as conversas a demarcação do lugar de estrangeiro que, conforme São Bernardo e Barbosa (2018), muitas vezes é uma violência ao refugiado que ele tenta superar por meio do acolhimento. Esta análise, portanto, é acompanhada de instrumentos de uma pesquisa

\footnotetext{
${ }^{11}$ Como é o caso da previsão de João Batista de Larcerda, no início do século XX, sobre o desaparecimento de "negros e mestiços" até o fim do século XX, que ainda não se cumpriu completamente, mas tem no genocídio e na miscigenação armas fortes. Ver mais em https://doi.org/10.1590/S0104-59702011000100013. Acesso em 24 fev. 2021.
} 
qualitativa, como notas de campo e entrevista semiestruturada. Para tanto, coletamos e utilizamos neste artigo a entrevista para fins de nossa análise. Chamamos de História de vida, acompanhando Chizzotti (2017), pela produção autobiográfica que a entrevista semiestruturada proporcionou, de maneira a reunir os aspectos de sua história de vida para o nosso interesse acadêmico. O próprio escopo desse levantamento aconteceu quando do encontro de pesquisador e participante em disciplina de metodologia da pesquisa durante 0 mestrado. A partir de então, os participantes da pesquisa assumiram o processo ético de colaborar uns com a pesquisa dos outros, de maneira que nosso participante assinou termo que delimita eticamente quando e como seus dados devem ser utilizados, bem como tornou a ser consultado, mais recentemente, sobre a utilização desses dados. Por isso, a análise dos dados está implicada pela conversa com esse participante, que também é pesquisador, durante a própria interpretação dos dados que eram coletados, de modo que seus dados foram mantidos em segurança até sua divulgação neste artigo.

Assim, uma pergunta que apareceu naquele momento e também neste é: por que estaria então esse participante renunciando, ao ter sua fluência reconhecida, ao lugar de um "igual" na língua/pátria? Ele nos traz algumas respostas:

Pesquisador: Você protagonizou algum momento que você falou diferente das pessoas? Como é que era a reação das pessoas?

José: No começo foi engraçado porque as pessoas ouvem meu Português e acham que eu falo muito, muito, muito. Aí depois elas estranham: "como é que você ta perguntando essa palavra?" Aí eu falo "Não sei, eu não sou daqui". "Não, é que você fala tão bem que é engraçado que você não saiba o que significa essa palavra". Ou, por exemplo, quando eu pronuncio alguma coisa muito (diferente), é o que eu te falei das vogais abertas e fechadas. Quando eu não sei aí o pessoal fica: "Aí, eu pensei que você não é brasileiro". Então essa é a reação do povo.

Como registra José del Veiga, sempre são os brasileiros a reificar uma relação de pátria e língua, ao pensar que, por falar um dado nível de português que se assimila a eles, ele não é estrangeiro. Como Pavlenko (2003) demonstrou em sua pesquisa, os próprios falantes que têm aquela língua como sua primeira são os que mais valorizam a diferença entre estrangeiro e conterrâneo, alimentando a importância do falante nativo.

José: eu não sei, mas acho que tem níveis de cobrança porque tem pessoas que vivem com estrangeiros que têm muito sotaque. Elas vão lidando com isso e eles privilegiam a educação. Eu acho que no meu caso eles têm essa monitoração mais rigorosa comigo. "Por que que você ta perguntando isso? Você tem que saber!" Então é uma relação que eu tou entendendo agora, que existem níveis de cobrança.

Ou seja, entendemos, com base nos dados, que o fato dos brasileiros em geral viverem criando uma categoria de estrangeiridade necessariamente revela a ânsia moderna do pensamento social brasileiro por se tornar uma nação liberal, uma pátria. Por isso, como 
destaca o participante, é sempre o brasileiro a criar seu suposto distintivo que o torna brasileiro, a língua:

Pesquisador: Você se sente estrangeiro?

José: Sim.

Pesquisador: Você sente que o fato de você falar fluentemente o Português aproxima você das pessoas?

José: Sim, eu acho que sim, porque a língua é a comunicação, né? Aí se eu não tou conseguindo me comunicar com você, eu nunca vou me aproximar. Mas, sim, eu acho que o fato de eu falar Português, ele já ajudou para que eu conhecesse mais pessoas.

Ao negar que não é um estrangeiro na língua, ele discorda das demais pessoas. "Eu tenho sotaque", diz. Assim, ele confirma, para o nosso ponto de vista, que a desestrangeirização é muitas vezes uma coisificação que as pessoas fazem do conceito de pátria/língua, pois ele sempre é desestrangeirizado, mesmo que não queira por supostamente falar bem a língua portuguesa:

Pesquisador: Você acha que você é desestrangeirizado pras pessoas quando você fala um Português mais fluente?

José: Pras pessoas sim.

É preciso, ao escutar José, defender que a iniciativa de desestrangeirização, num dado momento de imigração forçada, como é o caso dos refugiados contemporâneos, não seja uma ideia da cabeça do branco que teoriza e fomenta políticas públicas no ocidente a partir de si como quem se olha num espelho. Como exemplo disso, o White Paper on Intercultural Dialogue ${ }^{12}$, um documento lançado pelos Ministros das Relações Exteriores do Conselho da Europa da União Europeia em 2008 para tratar da atual fase de crise imigratória na modernidade europeia, promete buscar o fortalecimento de uma política multiculturalista de "tolerância" aos outros. Essa tolerância inclui tornar o outro como um de nós, convencionando um falso conceito democrático que não respeita de verdade a alteridade.

Quando, em sala de aula com diversos estrangeiros no Brasil, ele era ignorado sumamente pelos professores, ele lamentava:

José: Eu peguei 3 disciplinas na pós-graduação e em todas as turmas tem estrangeiros. Tem turma que tem japoneses, alemães, chineses. Eu às vezes percebo que os professores comentam: "E aí, como é que foi no seu país?", "E aí, vamos escutar os estrangeiros...", "Como é que é lá no seu país", aí eu me sinto invisível porque os professores nunca me perguntam. Nunca me perguntam: "Fidel, como é que é no seu país?". Ou tem professores tem muito interesse em saber como é que esse pessoal aprendeu português e

\footnotetext{
12 Ver o documento aqui: https://www.coe.int/t/dg4/intercultural/source/white\%20paper final revised en.pdf. Acesso em 24 fev. 2021.
} 
perguntam: "E aí, como é que foi no seu caso?", "como é que foi com você?", e não me pergunta, às vezes eu me sinto invisível.

Pesquisador: Você acha que o fato de você falar fluentemente o Português te invisibiliza?

José: Eu às vezes quero reivindicar isso. Que eu não sou brasileiro. É por isso que eu não sei, se eu fico indignado ou fico feliz. Porque eu gostaria de que me perguntassem.

Ou seja, José queria ser tratado como estrangeiro, mas não como estranho, como forma de ter sua experiência sensível de territorialidade de onde é, um país da América Central, reconhecida como alteridade naquele espaço.

Retomando Menezes de Souza (2018), a nacionalidade não aceita uma diversidade de origens, mas também busca apagar a origem nacional de povos não-brancos. Embora José não se autodeclare racialmente, sua experiência de latino mestiço diz respeito ao apagamento que sofre nesse corpo num país cuja experiência racial é de morte e estrangeirização dos corpos negros.

A personagem de Menezes de Souza (2018) e José não necessariamente precisam ser desestrangeirizadas na língua e nem fora dela se não quiserem. Essa tentativa, também violenta, configura a pressa ocidental por exportar um complexo da democracia liberal que se secularizou (ASAD, 2003), tornando todo lugar em pátria e analisando tudo pela régua da língua.

Apesar de tudo, ele diz querer ser visto como "de fora":

José: Tem amigos que me dizem "Ah, eu conheço um estrangeiro, mas você fala melhor". Sem eu perguntar, sem eu querer saber. Ou eu que digo "Eu conheci uma menina do México, que ela fala bem", aí a pessoa diz "Não, você fala bem". É uma coisa que eu quero e gosto, mas eu também sou de fora. Todo mundo fala: "É que você não é mais estrangeiro, é que você é brasileiro", "Liga não, é que todo mundo pensa que você é brasileiro" (grifos meus).

Ser de fora, ou ser estrangeiro, não implica em necessariamente ser mau. Aliás, povos pré-coloniais não brancocentrados tinham experiências distintas dos brancos sobre o estrangeiro, razão pela qual os portugueses chegaram com poucas naus em sua invasão e não foram dizimados na chegada.

\section{A língua como direito - o PLE em perspectiva}

Quando falamos em língua com direito no PLE, necessariamente estamos nos posicionando em direito como um espaço onde pode se estar, ainda que provisoriamente ao se falar, escrever, ouvir e categorizar o mundo através da linguagem. García E Wei (2014) teorizam esse direito linguístico como uma performance do sujeito nessa língua imposta, que chamam de translinguismo. 
May (2015), ao introduzir número do periódico Current Issues in Language Planning, analisa que os direitos linguísticos podem advir de uma série de fenômenos, sempre servindo para consagrar um direito, mas podendo reduzi-lo, como é o caso do monolinguismo.

Por isso, a conclusão deste artigo tem muito a ver como o falante quer ser visto. Durante muito tempo vimos pessoas brancas de fora tendo suas identidades originárias nacionais sendo respeitadas. Assim, quando José quer ser visto estrangeiro, não é por não gostar do Brasil e português (do qual, aliás, é profundo conhecedor e professor), mas porque entende que estar naquela língua não é abandonar suas identidades originárias.

Assim, o estudante de PLE refugiado deve e pode ser desestrangeirizado, desde que queira. Porém, dar condições de conforto a ele não pode significar inseri-lo forçadamente numa cultura brasileira branqueadora e problemática.

O PLE é estratégico porque o Brasil é um dos países que sempre honraram uma tradição diplomática que vem sendo quebrada. O ensino para estrangeiros não pode significar um fantasma que reproduz a maneira racista como as instituições do Norte tratam o imigrante falando aquelas línguas (ROSA; FLORES, 2017). Ao contrário, o Brasil também é símbolo de um pensamento crítico antirracista que precisa tomar corpo no ensino de português como segunda língua.

\section{Referências}

ALMEIDA FILHO, J. C. P. de. Linguística Aplicada: Ensino de línguas e comunicação. Campinas, SP: Pontes, 2005.

ALMEIDA FILHO, J. C. P. Dimensões comunicativas no Ensino de Línguas. 1. ed. Campinas: Pontes, 1993.

ALMEIDA FILHO, J. C. P.; LOMBELLO, L. C. O ensino de Português para estrangeiros. 2. ed. Campinas: Pontes, 1997.

ALMEIDA FILHO, J. C. P. de. Fundamentos de Abordagem e Formação no Ensino de PLE e de Outras Línguas. Campinas, SP: Pontes Editores. 2011.

ALOMBA RIBEIRO, M. D. Los conectores argumentativos com los aprendices hispano hablantes de português. Tese (Doutorado em Linguística Aplicada). Universidade de Alcalá de Henares, 2005.

ANDERSON, B. Comunidades imaginadas: reflecções sobre a origem e a expansão do nacionalismo. Lisboa: Edições 70, 1991.

ANZALDUA, G. Borderlands: the new mestiza = La frontera. San Francisco: Aunt. Lute, 1987.

ASAD, T. Formations of the Secular: Christianity, Islam, Modernity. Stanford: Stanford University Press, 2003. https://doi.org/10.1515/9780804783095

AZEVEDO, C. M. M. Onda negra medo branco: o negro no imaginário das elites - século XIX. Rio de Janeiro: Paz e Terra, 1987. 
BERTOLDO, E. S. O contato-confronto com uma língua estrangeira: a subjetividade do sujeito bilíngue. In: CORACINI, M. J. (Org.) Identidade e Discurso. Campinas: Editora da Unicamp, 2003, p. 83-118.

BLOCK, D. Social class in Applied Linguistics. Londres: Routledge, 2013. https://doi.org/10.4324/9781315871141

BRETÃS, B. Comunicação mediática no processo ensino/aprendizagem. In: COSTA, J. W. da; OLIVEIRA, M. A. M. (orgs.) Novas linguagens e novas tecnologias: educação e sociabilidade. Petrópolis, RJ: Vozes, 2004. p. 81-110.

BYRAM, M. Teaching and Assessing Intercultural Communicative Competence. Clevedon, UK: Multilingual Matters, 1997.

CANAGARAJAH, S.; LIYANAGE, I. Lessons from pre-colonial multilingualism. In: BLACKLEDGE, A.; CREESE, A. The Routledge Handbook of Multilingualism. London: Routledge, 2012. p. 4965.

CASTRO, Y. P. Marcas de Africania no Português Brasileiro. Africanias.com, v. 01, p. 1-7, 2011.

CESAIRE, A. Discurso sobre o colonialismo. Porto: Cadernos para o diálogo, 1971.

CHIZzOTTI, A. Pesquisa em Ciências Humanas e Sociais. 12. ed. São Paulo: Cortez Editora, 2017.

FANON, F. Pele Negra Mascaras Brancas. Salvador: EdUFBA, 2008.

https://doi.org/10.7476/9788523212148

FERREIRA, A. J.; CAMARGO, M. O racismo cordial no livro didático de língua inglesa aprovado pelo PNLD. Revista da ABPN, v. 6, n. 12. p. 177-202. 2013.

GARCÍA, O.; WEI, L. Translanguaging: Language, bilingualism and education. Basingstoke, UK: Palgrave Macmillan, 2014. https://doi.org/10.1057/9781137385765

GILROY, P. O Atlântico Negro. Modernidade e dupla consciência, São Paulo, Rio de Janeiro, 34/Universidade Cândido Mendes - Centro de Estudos Afro-Asiáticos, 2001.

GONZALEZ, L. A categoria político-cultural de amefricanidade. Tempo Brasileiro, Rio de Janeiro, n. 92/93, p. 69-82, 1988.

HALL, S. A identidade cultural na pós-modernidade. 3. ed. Rio de Janeiro: DP \& A, 1999.

IRVINE, J.; GAL, S. Language ideology and linguistic differentiation. In: KROSKRITY, P.V. (Org.). Regimes of Language: Ideologies, Polities, and Identities Santa Fe. NM: School of American Research Press, 2000. p. 35-83.

KUBOTA, R. Rethinking the superiority of the native speaker: Toward a relational understanding of power. In: NERIKO, M. D. (Ed.). "Native speakers" revisited: Multilingualism, standardization, and diversity in language education. Mouton de Gruyter, 2009. p. 233-247. https://doi.org/10.1515/9783110220957.233

LEFFA, V. Identidade e aprendizagem de línguas. In: SILVA, K. A.; DANIEL, F. G.; KANEKOMARQUES, S. M.; SALOMÃO, A. C. B. (Org.). A formação de professores de línguas - Novos Olhares - Volume II. Campinas, Pontes Editores, 2013. p. 51-81. 
MAKONI, S.; PENNYCOOK, A. (Org.). Disinventing and Reconstituting Languages. Clevedon: Multilingual Matters, 2007. https://doi.org/10.21832/9781853599255

MARCHAND, M. Português para estrangeiros. Porto Alegre: Edições Sulinas, 1957.

MASTRELLA-DE-ANDRADE, M. R. Crenças sobre si, crenças sobre erros: identidades em jogo na sala de aula de LE. In: CONCEIÇÃO, M. P. (Org.). Experiências de Aprender e Ensinar Línguas Estrangeiras: Crenças de Diferentes Agentes no Processo de Aprendizagem. Capinas: Pontes Editores, 2011. p. 223-258.

MASTRELLA-DE-ANDRADE, M. R. Pós-modernidade e ensino de línguas estrangeiras... Horizontes de Linguística Aplicada, v. 9, n.1, p. 102-117, 2010. https://doi.org/10.26512/rhla.v9i1.813

MASTRELLA-DE-ANDRADE, M. R.; RODRIGUES, J. A. A construção de identidades no livro didático de inglês: classe social, raça e o outro. In: FERREIRA, A. J. (Org,). As políticas do livro didático e identidades sociais de raça, gênero, sexualidade e classe em livros didáticos. Campinas, SP: Pontes, 2014. p. 143-162.

MATOS, F. G. de. Quando a prática precede a teoria: a criação do PBE, In: ALMEIDA FILHO J.C.P. de; LOMBELLO, C. L. (Orgs.) O ensino de Português para estrangeiros: pressupostos para o planejamento de cursos e elaboração de materiais. Campinas: Pontes, 1997.

MAY, S. Language rights and language policy: addressing the gap(s) between principles and practices, Current Issues in Language Planning, v. 16, n. 4, p. 355-359, 2015. https://doi.org/10.1080/14664208.2014.979649

MENDES, E. O português como língua de mediação cultural: por uma formação intercultural de professores e alunos de PLE. In: MENDES, Edleise. (Org.). Diálogos Interculturais - Ensino e formação em português língua estrangeira. 1.ed. Campinas-SP: Pontes Editores, 2011. p. 139-158.

MENEZES DE SOUZA, L. M. T. M. de. The Goan Patient: a cultural speculation. Interdisciplinary journal of Portuguese diaspora studies, v. 07, p. 413-433, 2018.

MIGNOLO, W. Local Histories/Global Designs. Chichester: Princeton University Press, 2000.

MUNANGA, K. Rediscutindo a mestiçagem no Brasil. Identidade Nacional versus Identidade Negra. 2. ed. Belo Horizonte: Editora Autêntica, 2004.

SANTOS, G.N. dos. E a história não acabou... A representação da identidade de classe social no livro didático de língua inglesa. 2016. 164 f. Dissertação (Mestrado em Linguística Aplicada). Universidade de Brasília, 2016.

NASCIMENTO, G. Moderno, pós-moderno ou pós-colonial? A (im)possibilidade de Definição da identidade do ensino de língua estrangeira. Revista Fórum Identidades, v. 15, p. 265-286, 2014.

NASCIMENTO, G. Racismo linguístico: os subterrâneos da linguagem e do racismo. 1. ed. Belo Horizonte: Letramento Editorial, 2019.

NORTON, B. Language, identity, and the ownership of English. TESOL Quarterly, v. 31, n. 3, p. 409-429, 1997. https://doi.org/10.2307/3587831

NORTON, B.; TOOHEY, K. Identity, language learning, and social change. Language Teaching, v. 44, n. 4, p. 412-446, 2011. https://doi.org/10.1017/S0261444811000309 
PAVLENKO, A. "I never knew I was a bilingual": Reimagining teacher identities. TESOL. Journal of Language, Identity, and Education, v. 2, p. 251-268, 2003. https://doi.org/10.1207/S15327701JLIE0204 2

ROCHA, S. O poder da linguagem na Era Vargas: o abrasileiramento do Imigrante. 6o Círculo de Estudos Linguísticos do Sul Censul. 2004. p. 1-5.

ROSA, J.; FLORES, N. Unsettling race and language: Toward a raciolinguistic perspective. Language in Society, v. 46, n. 5, p. 621-647, 2017.

https://doi.org/10.1017/s0047404517000562

SÁ, R. L. Imigrantes hispano-americanos, (inter)culturalidade crítica e língua portuguesa. Revista de estudos acadêmicos de Letras, v. 10, p. 63-73, 2017.

SANTOS, B. Pela mão de Alice: o social e político na pós-modernidade. 5. ed. São Paulo: Cortez, 1999.

SANTOS, G. N. dos; ALOMBA RIBEIRO, M. D. O professor crítico-reflexivo e o livro didático de PLE. Revista de Letras Norte@mentos, v. 6, n. 12, p. 53-72, 2013.

SANTOS, M. Por uma outra globalização: do pensamento único à consciência universal. Rio de Janeiro: Record, 2000.

SÃO BERNARDO, M. A.; BARBOSA, L. M. A. Ensino de português como língua de acolhimento: experiência em um curso de português para imigrantes e refugiados(as) no Brasil. Fólio Revista de Letras, v. 10, p. 475-493, 2018. https://doi.org/10.22481/folio.v10i1.4045

SILVERSTEIN, M. Language structure and linguistic ideology. In: CLYNE, P. R.; HANKS, W. F.; HOFBAUER, C. L. (Orgs.). The Elements: A Para-Session on Linguistic Units and Levels. Chicago: Chicago Linguistic Society, 1979.

SMITHERMAN, G. Ebonics, King, and Oakland: Some folk don't believe fat meat is greasy. Journal of English Linguistics, n. 26, p. 97-107, 1998.

https://doi.org/10.1177/007542429802600202

SOUZA, J. A tolice da inteligência brasileira, ou, como o país se deixa manipular pela elite. 2. ed. Rio de Janeiro: Leya, 2018.

SOUZA, L. M. T. M. de. Glocal Languages, Coloniality and Globalization from below. In: GUILHERME, M. M.; SOUZA, L. M. T. M. (Org.). Glocal Languages and Critical Intercultural Awareness: the South Answers back. Nova York: Routledge, 2019. p. 17-41. https://doi.org/10.4324/9781351184656-2

SOUZA, N. S. Tornar-se negro. Rio de Janeiro: Edições Graal, 1983.

STROUD, C.; QUENTIN, E. W. Multilingualism as utopia: Fashioning non-racial selves. Meaning Making in the Periphery - Aila Review, n. 30, p. 167-188, 2017. https://doi.org/10.1075/aila.00008.str

TELLES, E. Pigmentocracies: Ehtnicity, Race and Color in Latin America. The University of North Carolina Press, 2014.

TILIO, R. C.; A representação do mundo no livro didático de inglês como língua estrangeira: uma abordagem sócio-discursiva. The Especialist, v. 31, p. 167-192, 2010. 
TILIO, R. C.; JÚNIOR, E. M. de S. Gênero e sexualidade em livros didáticos: impactos da avaliação do PNLD? In: FERREIRA, Aparecida de Jesus (Org.). As políticas do livro didático e identidades sociais de raça, gênero, sexualidade e classe em livros didáticos. Campinas, SP: Pontes, 2014.

VANDRICK, S. The role of social class in English Language Education. Journal of Language, Identity and Education, v. 13, n. 2, 2014. p. 85-92.

https://doi.org/10.1080/15348458.2014.901819

Recebido em: 03/08/2020.

Aceito em: 01/12/2020. 